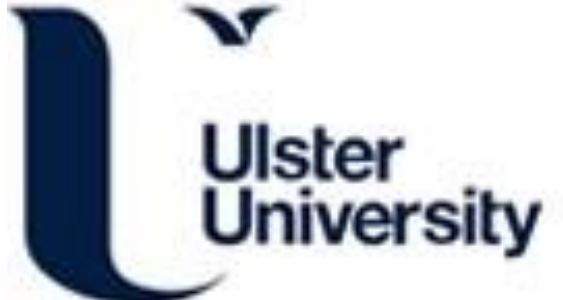

\section{Improved crush energy absorption in 3D woven composites by pick density modification}

Neale, G., Dahale, M., Yoo, S., Toso, N., Mc Garrigle, C., Quinn, JP., Kelly, J., Mcllhagger, AT., Archer, E., \& Harkin-Jones, E. (2020). Improved crush energy absorption in 3D woven composites by pick density

modification. Composites Part B: Engineering, 192, [108007]. https://doi.org/10.1016/j.compositesb.2020.108007

Link to publication record in Ulster University Research Portal

\section{Published in:}

Composites Part B: Engineering

Publication Status:

Published (in print/issue): 01/07/2020

DOI:

10.1016/j.compositesb.2020.108007

\section{Document Version}

Author Accepted version

\section{General rights}

Copyright for the publications made accessible via Ulster University's Research Portal is retained by the author(s) and / or other copyright owners and it is a condition of accessing these publications that users recognise and abide by the legal requirements associated with these rights.

\section{Take down policy}

The Research Portal is Ulster University's institutional repository that provides access to Ulster's research outputs. Every effort has been made to ensure that content in the Research Portal does not infringe any person's rights, or applicable UK laws. If you discover content in the Research Portal that you believe breaches copyright or violates any law, please contact pure-support@ulster.ac.uk. 
Improved Crush Energy Absorption in 3D Woven Composites by Pick Density Modification

Geoffrey Neale ${ }^{a *}$, Monali Dahale , Sanghyun Yoo ${ }^{\mathrm{b}}$, Nathalie Toso ${ }^{\mathrm{b}}$, Cormac McGarrigle ${ }^{\mathrm{c}}$, Justin Quinn ${ }^{\mathrm{c}}$, John Kelly ${ }^{\mathrm{a}}$, Alistair McIlhagger ${ }^{\mathrm{a}}$, Edward Archer ${ }^{\mathrm{a}}$, and Eileen Harkin-Jones ${ }^{\mathrm{a}}$

a: Engineering Research Institute, Ulster University, Shore Road, Newtownabbey, BT37 0QB, United Kingdom

b: Institute of Structures and Design, German Aerospace Centre (DLR), Stuttgart

c: Centre for Engineering and Renewable Energy, Ulster University, Magee Campus, BT48 7JL, United Kingdom

*corresponding Author \& Email: Geoffrey Neale \& neale-g@ulster.ac.uk

Abstract: Although 3D woven composites have exceptional out-of-plane properties, there is a lack of understanding for these materials in crash application in automotive and aerospace industries. To encourage the use of 3D wovens in crashworthy automotive structures, knowledge must be gained so that designers can adjust the highly flexible weave parameters to create tailor-made performance materials. Here we show that fabric pick density causes large changes in progressive failure modes and associated energy absorption, particularly in the dynamic regime, where the quasi-static to dynamic energy absorption loss typical of composites is completely removed. Compression and flexure properties, which are known to be linked to crash performance in composites, are also investigated for these 3D woven layer-to-layer interlock carbonepoxy composite structures. 3D fabric preforms are manufactured in three different pick densities: 4,10 \& 16 wefts $/ \mathrm{cm}$. with a constant warp density of 12 warps $/ \mathrm{cm}$ from carbon fibres. Increasing the pick density improved specific energy absorption (SEA) even in relatively inefficient progressive failure modes like folding, which has not previously observed in composite materials. SEA values up to $104 \mathrm{~J} / \mathrm{g}$ (quasi-static) and $93 \mathrm{~J} / \mathrm{g}$ (dynamic) are recorded. This work shows that minor weft direction (transverse) weave changes can lead to sizeable improvements in warp direction (axial) energy absorption without fundamentally redesigning the weave architecture. 
Keywords: A. 3-Dimensional reinforcement; B. Impact Behaviour; E. Weaving; Energy Absorption.

1. Introduction

Crashworthiness describes a structure's ability to absorb energy through progressive failure whilst maintaining a given load profile during the energy absorbing event [1]. Typically, crash absorbers consist of a system of crash rails/tubes found at the front end of passenger cars and trains, and in collapsible floor supports in the keel of aircraft [2]. These crash rail/tube structures all absorb energy via progressive crushing, which dictates controlled and predictable failure progressing down the structure as the crush zone advances [3].

Specific Energy Absorption (SEA) is typically used to quantify the crashworthiness of a structure and is a function of both material and geometry [2]. Research has mostly been focussed on 2D composites using doubly symmetric, closed-section structures like cylinders, squares and other equal-sided polygons [4-6]. These structures provide SEA values typically in the range between 20 and $80 \mathrm{~J} / \mathrm{g}$. Many studies have been carried out that investigate the effect of specimen geometry [4], lay-up [7,8] and varying fibre/matrix combinations $[9,10]$ on energy absorption in $2 \mathrm{D}$ composite structures.

3D woven composites continue to gain traction across different transportation industries with their most extensive applications in the crash box of the Lexus LFA, the passenger compartment of the BMW i3 [11] and the fan module of the CFM International LEAP engine [12]. When comparing fundamental 3D woven architectures, orthogonal architectures tend to be preferred and exhibit the best mechanical performance [13], damage tolerance [14,15] and SEA (up to about $90 \mathrm{~J} / \mathrm{g}$ ) [16,17]. For this application, their greatest disadvantage is the high degradation of SEA with increasing strain rate in the dynamic regime. Orthogonal architectures can lose about one third of their SEA capability in the transition from quasi-static to high-speed dynamic loading [12]. This contrasts with layer-to-layer architectures which show only a one-sixth loss in that transition [12,18]. Additionally, layer-to-layer architectures have better conformability around complex geometries and therefore have been chosen for this study [18].

At present, 3D woven composites have been mostly unexplored for crashworthiness applications. A limited number of out-of-plane impact scenarios have been investigated $[12,19,20]$ but very little literature exists about crashworthy 3D woven structures. Likely reasons for this are: 1) a lack of a comprehensive fundamental understanding of the relationship between weave variations within a specific architecture and the corresponding mechanical properties; and 2) the high initial investment required for loom equipment. 
Additionally, researchers tend to focus on comparisons between the three fundamental weave architectures [21] (orthogonal, angle-interlock and layer-to-layer) leaving the effects of more basic textile property modifications insufficiently investigated. These weave parameters, such as pick density (sometimes referred to as weft density), warp density, float length and tow size, are known to have a major effect on 3D fabric properties through features like crimp, waviness, tow misalignment and resin rich areas, which are inherent to the manufacturing process [22-25].

The crashworthy behaviour of 3D woven composites is not at all understood because of complexities associated with the presence of the through-thickness reinforcement and there is need for a greater understanding of the failure mechanics given their increasing usage. This research aims to investigate the axial crushing energy absorption performance and progressive failure mechanisms in 3D woven layer-tolayer carbon/epoxy composites. By adjusting pick density, a textile property which can be altered without any changes to the loom set up (which in this case took over 100 hours approximately), it is possible to tailor properties to improve SEA while keeping the fundamental fabric architecture unchanged.

\section{Materials \& Manufacture}

\subsection{Resin and Fibre Systems}

The resin system used in this work was PRIMETM20LV [26]. This resin was selected for its low working viscosity and extended working time. 3D woven preforms were manufactured using TORAY T700S-50C 12k carbon fibre yarns. [27].

\subsection{D Fabric Architecture}

Figure 1 shows the layer-to-layer 3D fabric architecture manufactured in three textile iterations with pick densities of 4, 10 and 16 wefts $/ \mathrm{cm}$. The 3D fabric architecture consisted of three warp layers (blue), four weft layers (green) and three warp binders (red) which connect weft layers immediately above and below each binder. All textiles have a constant warp density of 12 warps $/ \mathrm{cm}$. The fabric preforms are referred to as PD1, PD2 and PD3 for low (4 wefts/cm), medium (10 wefts $/ \mathrm{cm})$ and high $(16$ wefts $/ \mathrm{cm})$ pick densities respectively (Figure 1). Fabric designs and lift plans were developed using the ScotWeave software and used to operate the DATAWEAVE controlled jacquard loom at Ulster University with the assistance of Axis Composites Ltd. 3D woven preform properties for all the specimens are shown in Table 1. Further textile design details about this architecture can be found in Dahale et al. [28]. 


\subsection{Specimen Manufacture}

The omega-shaped specimen geometry is based on previous work by the German Aerospace Centre (DLR) [29]. A diagrammatic representation of the specimen geometry is shown in Figure 2a and consists of a half-circular section (green) with two small flanges at either end of the semi-circle (blue). The geometry was selected for its ease of manufacture and proven stability. Moreover, the lack of a standard for this type of progressive crush test requires a consistent coupon with which the performance of the various architectures could be tested. Preforms were infused via resin transfer moulding (RTM) and cured at $50^{\circ} \mathrm{C}$ for 16 hours. Test coupons were cut to $60 \pm 2 \mathrm{~mm}$ for quasi-static specimens and $90 \pm 2 \mathrm{~mm}$ long for dynamic specimens, both with a thickness of $2.5 \pm 0.5 \mathrm{~mm}$. Specimen characteristics are presented in Table 2. A trigger was machined into one end of the specimens in the form of an angled saw-tooth pattern (Figure 2b). Traditional chamfers and other triggers which are non-symmetric through the wall thickness can introduce a small bending moment due to the initially uneven loading on specimen walls [30]. 3D woven composites have a much higher degree of crimp included in their weave compared to 2D composites [22]. As a result, the material is more susceptible to buckling during triggering [31,32]. Saw tooth triggers were used because their initial contact load distribution at the leading edge of crush is uniform in the through-thickness direction [33]. For testing purposes, the test specimens were constrained at their base in either a 10mm deep resin base (quasi-static specimens) or aluminium base (dynamic specimens).

3. Testing

\subsection{Crush Testing}

Quasi-static crush testing was performed on an electromechanical Instron 5500R Universal Testing System (UTS) with a 100kN load cell. Three specimens of each iteration were crushed between two polished parallel steel plates with an initial crosshead displacement of $2 \mathrm{~mm} / \mathrm{min}$ for the first $15 \mathrm{~mm}$ of displacement. The loading rate was then increased to $20 \mathrm{~mm} / \mathrm{min}$ until the end of crush $(40 \mathrm{~mm}$ total displacement).

Dynamic testing was conducted on an Instron High Strain VHS - 100/20 with a 100kN load cell. Specimens were fixed to the bottom steel plate with strong double-sided tape and crushed between the two steel plates. Three specimens of each iteration were crushed to $60 \mathrm{~mm}$ crosshead displacement with an initial impact velocity of $8.5 \mathrm{~m} / \mathrm{s}$. 
In the analysis of both quasi-static and dynamic specimens, the SEA is calculated as the area under the steady-state crush region of the load-displacement curve divided by the mass of the crushed portion of the specimen, expressed by the equation [34]:

$$
S E A=\frac{\int F d x}{M}
$$

Where $\mathrm{E}$ is the energy absorbed in joules, $\mathrm{F}$ is the force in kilonewtons, $\mathrm{x}$ is the displacement in millimetres and $\mathrm{M}$ is the mass of the damaged portion of the structure in grams.

The Crush Force Efficiency (CFE) is defined as the ratio between the average sustained crushing load $\left(\mathrm{F}_{\text {avg }}\right)$ and the initial peak load $\left(\mathrm{F}_{\max }\right)$ and expressed as a percentage [35]:

$$
C F E=\frac{F_{\text {avg }}}{F_{\max }} \%
$$

Where CFE is the crush force efficiency expressed as a percentage, Fmax is the initial peak load in kilonewtons and Favg is the average sustained crushing load in kilonewtons.

\subsection{Compression}

Compression testing was performed in line with the Boeing modified ASTM D695 standard [36] on an electromechanical Instron 5500R UTS machines with a $100 \mathrm{kN}$ load cell. The original test was modified by changing the specimen shape and reducing the gauge length to $4.8 \mathrm{~mm}$ to avoid buckling of the test specimens. Specimens were then fitted into an anti-buckling jig and compressed with a constant crosshead displacement of $2 \mathrm{~mm} / \mathrm{min}$. Five specimens were tested for each iteration.

\subsection{Three Point Bending}

Three point bending tests were performed using ASTM D7264 [37] on an electromechanical Instron 5500R UTS with a $100 \mathrm{kN}$ load cell. The span to thickness ratio used for the five specimens tested using this standard was 32. A crosshead displacement of $1 \mathrm{~mm} / \mathrm{min}$ was used to perform these tests. Five specimens were tested for each iteration. 


\section{Results \& Discussion}

\subsection{Crushing Observations}

The results for quasi-static crush tests of the omega-shaped specimens are presented in Table 3 and typical load-displacement curves are given in Figure 3. PD1 specimens show the highest SEA at 104.8 J/g which then decreased by $20 \%$ to $84.2 \mathrm{~J} / \mathrm{g}$ in PD2 specimens, followed by a $6 \%$ increase to $88.5 \mathrm{~J} / \mathrm{g}$ in PD3 specimens.

PD1 specimens fail via a stable splaying dominated event with the formation of inward and outward fronds (Figure 5a). Energy is primarily absorbed by delamination of the central crack, axial frond tearing and the bending of fronds.

PD2 specimens fail predominantly through mixed-mode failure, in which a brittle fracture occurs in the earlier stages of crush followed by progressive folding (Figure 5b). Energy is absorbed initially by central yarn crushing and then by compaction in the shallow debris wedge since the delamination front is resisted by binder yarns. External plies form short inward and outward fronds which absorb further energy via the initiation and propagation of discontinuous axial cracking, which is often arrested by weft yarns at the base of the frond.

In PD3 specimens (Figure 5c), progressive folding is observed from the onset of crush alongside some secondary crushing of the material in contact with the crush platen (e.g. fractured edges, etc.). Continuous axial cracking along the material is not visible, with very little material detaching from the sample. During folding, energy is absorbed by fibre fracture and pull-out on the tensile side of the bend radius and by delamination and micro-buckling on the compressive side of the bend radius. Further energy is absorbed by local, short delaminations in the composite which are quickly arrested by the tightly packed binders.

The dynamic crush results are also displayed in Table 3 and their corresponding typical loaddisplacement curves are given in Figure 4. PD1 specimens exhibit a SEA of $78.1 \mathrm{~J} / \mathrm{g}$ which decreased by $10 \%$ to $70.1 \mathrm{~J} / \mathrm{g}$ in PD2 specimens, followed by a $33 \%$ increase to $92.9 \mathrm{~J} / \mathrm{g}$ in PD3 specimens. However, PD3 specimens still achieve a 20\% higher SEA than PD1 specimens. All dynamically tested specimens failed by splaying (Figure 6). Primary energy absorption results from the initiation and propagation of a central plane crack and axial tearing between fronds. 
In PD1 specimens, weft tow rupture promotes the creation of more fronds, which have little flexural resistance. Short, almost non-existent fronds result from large amounts of axial and transverse cracking/tearing between fronds. Energy is absorbed by this cracking and by the rupture of the axial yarns in the fronds (Figure 6a). This failure resembles brittle fracture failure and, to some extent, is a combination of brittle fracture and splaying, where there is some crushing of the internal yarns.

In PD2 specimens, shorter delamination cracks provide less curvature in the fronds which instead break off and do not continue to absorb energy via significant amounts of bending and friction (Figure 6b).

In PD3 specimens, one large internal frond is formed along with only two large external fronds divided by a central axial tear(Figure 6c). Tow fracture from the splitting of the material about a central delamination crack is heavily resisted by the high number of binder turns present in the architecture. Energy is absorbed by binder tow rupture at the central delamination crack, through the bending resistance of rigid fronds and through friction between the frond surfaces and the crush platen.

\subsection{Compression}

From Figure $7 \mathrm{a}$, it is evident that with increasing pick density there are significant improvements in the compressive strength. There is an increase of $5 \%$ and $12 \%$ in compressive strength from PD1 to PD2 and PD2 to PD3 respectively. According to the work of Stig et al. [22], this moderate increase in compressive strength is perhaps the direct result of higher geometric regularity in the composite in PD2 and PD3 specimens. When the pick density is increased, the initial 1 binder turn/layer (PD1) is compressed into a much smaller space because the binder yarn must track around 2.5 (PD2) and 4 (PD3) weft yarns within a unit cell. Due to increased binder points in the gauge length of $4.8 \mathrm{~mm}$, more load is required for the specimens to fail. Compressive failure transitions from interlaminar brooming failure to higher energy transverse shearing as pick density increases (Figure 8).

\subsection{Three-point Bending}

Between PD1 and PD3 specimens, there is an overall increase of $72 \%$ and $50 \%$ in flexure strength and modulus respectively (Figure 7b). The more compact structure in PD3 as compared to PD1 and PD2 makes this specimen stiffer and more resistant to flexural deformation. The improved flexure strength in PD3 specimens is due to its tightly packed structure along with a significantly higher number of interlocking points as compared to PD1 specimens. In PD1 specimens the binder yarns are not homogenously stacked 
due to a loosely packed structure. Cracks initiating at the surfaces and at resin rich regions are not stopped by the next binder because these are not stacked ideally (Figure 9a). This leads to longer delamination cracks and significantly more through-thickness cracking in PD1 specimens compared to PD2 (Figure 9b) and PD3 (Figure 9c) specimens. All three warp yarns are ruptured in PD1 specimens whereas in PD2 and PD3 specimens the crack does not propagate through the thickness of the specimens. This damage initiation is similar to what is seen in bending tests conducted by Gao et al.[15] on 3D orthogonal architectures, where cracks propagate from the surfaces to the interior spreading along the yarn system. Those researchers also report similar matrix cracking, debonding and fibre breakage as the main failure mechanisms.

\subsection{Effect of Pick Density on Quasi-Static Crush}

Figure 10 graphically compares the average SEA amongst specimens. PD1 specimens behave very similarly to a $2 \mathrm{D}$ materials and exhibit classic high energy splaying failure (Figure $5 \mathrm{a}$ ). That behaviour combined with its low mass/mm (Table 2) provides the highest quasi-static SEA. This low pick density (4 wefts $/ \mathrm{cm}$ ) is such that over $70 \%$ of the fibres are oriented in the axial direction of loading, much higher than any of the other configurations, with a low number of spaced out binding points. This allows for the sustaining of higher stresses without the buckling effects caused by the out-of-plane fibre deviation seen in PD2 and PD3 specimens. In this way, the material behaves more like a 2D laminate with some small amount of through-thickness reinforcement. Comparable quasi-static SEA values (just over 100J/g) are recorded by Jackson et al. [38] and Feraboli et al. [30] for 2D woven omega-shaped laminates. It can be said that PD1 specimens exhibit a high SEA for the same reasons as those mentioned in the literature for 2D laminates, that is that they have a high percentage of load carrying yarns alongside hoop reinforcing yarns.

In PD2 (and PD3) specimens, the greater number of binder turns caused by increasing the pick density prevents the creation of a central delamination crack. Instead, through-thickness shear fracture and local buckling is the result of compressive loading (Figure 8b). As a result, progressive folding is predominant in PD2 and PD3 specimens.

Going from PD2 to PD3 specimens, failure transitions from a mixed-mode (splaying and folding) failure mechanism to pure progressive folding (Figure 11). Brittle fracture or splaying is the expected failure mode usually seen in 2D carbon-epoxy crush specimens [38]. Progressive folding is unusual in more brittle composites, like carbon, and is regarded as a lower energy failure mode in brittle composites [34]. The presence of progressive folding in these specimens is brought about by the interplay between axial and 
hoop reinforcement in the structure. This is like the effect of 2D composite lay-up and orientation or braiding angle in braided composites. Jackson et al. [38] investigated lay-up orientation in 2D woven, unidirectional carbon fibre omega-shaped structures. The researchers observed fewer axial splits with increasing hoop reinforcement. Splaying failure was observed in all specimens, showing improved SEA with increasing hoop reinforcement, similarly to what is observed in this research. Priem et al. [39] explored the influence of braiding angle in 2.5D braided composites. They reported an increased SEA and transition from splaying to progressive folding in closed-section specimens with an increase in braiding angle.

Figure 7a shows that increasing the pick density increases the compressive strength of the material in the warp direction due to the presence of higher energy transverse shear failure in PD3 specimens (explained in Section 4.2). This behaviour was also reported in Dahale et al. [24] in which the effect of increasing pick density on the mechanical properties of glass-fibre composites was investigated. Similarly to what was concluded in research by Dahale et al. and Stig et al. [22], it was found that in 3D composites, the compressive strength of the material is largely affected by the through-thickness interlacement of the yarns. Crimp and tow misalignment, although inherent in these materials, have a detrimental effect on the compressive behaviour of 3D woven composites. Greater compactness of the architecture in PD3 specimens reduces crimp in warp yarns and provides greater in-plane tow alignment in both warp yarns and binders. There a $12 \%$ increase in compressive strength on the transition from PD2 to PD3 respectively.

In specimens where progressive folding is present (PD2 and PD3), the energy absorption is highly dependent on bending rigidity. The increased SEA in PD3 specimens can be attributed to its higher flexural properties (Figure 7b). Flexural failure in this material is fibre-dominated and loading can be sustained well beyond the initiation of failure due to the constant debonding, pull-out and straightening of yarns. Upon loading, more energy is required to straighten PD3 yarns than PD2 yarns before failure. This is because PD2 yarns are less constricted in a looser architecture. There are twice the number of interlocking points in PD3 specimens which prevent the crack propagation in both the in-plane and out-of-plane directions. Delamination cracks in PD3 specimens are shorter and more numerous (Figure 11b), which allow for the debonding of more yarns which then pull-out and straighten to sustain bending. This can also be seen in PD2 specimens (Figure 11a), but the process is less efficient with larger cracks that jump to surfaces. Delaminations near the surface in PD2 specimens initiate transverse shear failure and complete fracture 
rather than continuous pull out (Figure 5a). However, it can be said that this progressive folding mechanism in PD3 specimens is not as efficient (lower CFE) as the failure in PD2 or PD1 specimens (Table 3).

\subsection{Effect of Pick Density on Dynamic Crush}

When the pick density increases from PD1 to PD2, the Favg is mostly unchanged. This suggests that a larger number of hoop reinforcing yarns results in lower hoop stresses per yarn. Stresses in PD2 weft yarns do not achieve values high enough to promote extensive axial tearing beyond the crush front which is necessary to promote frond formation and central plane delamination.

In PD3 specimens, where there is a large proportion of weft yarns, hoop stresses in individual yarns are not sufficiently high to allow for multiple frond formation of the splayed material (Figure 6c). One large internal frond is formed along with only two large external fronds divided by a central axial tear. Tow fracture from the splitting of the material about a central delamination crack is heavily resisted by the high number of binder turns present in the architecture. The unit cell size shrinks by $42 \%$ (PD2 to PD3) and corresponds to just about double the number of binders turns per centimetre in the warp direction. The fronds created in PD3 specimens are much larger and more compared to that of PD2 specimens (Figure 6). These larger fronds have higher bending rigidity than those in PD2 specimens and can better help resist the motion of the crush plate. This is not seen in 2D laminates, where frond formation is synonymous with secondary delamination cracking in the fronds. Frond layers slip between each other and are unable to provide similar rigidity $[1,40]$.

In all cases, dynamic tests cause the ejection of debris during testing. This debris comes primarily from the outermost yarn layers which experience compression and transverse shear failure. The majority of these particles are about the size of a weft yarn's width by half its wavelength (the distance to the next warp yarn). As pick density increases to PD3, weft yarn width shrinks allowing for the ejection of smaller, more numerous particles and hence more energy absorption. Internal yarns experience interlaminar shearing which allows for the local, parallel to fibre cracks that free up the material to bend and maintain high frond curve radii because of its higher flexural strength (Figure 7b)

It is difficult to examine the frictional element of energy absorption because of the complexities associated with its quantification [41]. However, researchers have confirmed that the friction between yarn layers and between fronds and crush platens play a very significant role (up to 50\%) in energy absorption in the dynamic regime [38,42]. Based on the examination of the failure progression and the final crush 
geometry, it can be concluded that only PD2 and PD3 specimens are able to absorb significant amounts of energy through friction. This is because these specimens form significant fronds during crush whereas that is not true in PD1 specimens (Figure 6a). The higher weft yarn content in PD3 specimens leaves frond surfaces visually rougher than in PD2 because of the greater undulation of the weft yarns in the structure. This results in increased friction in PD3 over PD2 specimens and hence contributes to greater SEA. This qualitative observation is supported by the higher CFE (and hence $\mathrm{F}_{\text {avg }}$ ) in PD3 specimens which is associated with both this increase in frictional resistance and bending rigidity (Figure 7b).

\subsection{Dynamic versus Quasi-static Energy Absorption}

The failure modes observed in quasi-static and dynamically tested specimens in PD2 and PD3 specimens differ completely in these experiments. This was unexpected because experiments conducted on 2D omega-shaped laminates by Jackson et al. [38], David et al. [43] and on sinusoidal 3D woven specimens by Goering et al. [12] showed no macroscale differences between the failure modes present in quasi-static and dynamically tested specimens.

A reduction in SEA when loading transitions from quasi-static to dynamic is expected in crush analysis $[12,44]$. With increasing pick density the discrepancy between quasi-static and dynamic SEA decreases (Figure 10). In experiments conducted by Goering et al. [12], the layer-to-layer type architecture (referred to as ply-to-ply in that paper) showed over $20 \%$ decrease in SEA when quasi-static $(50 \mathrm{~mm} / \mathrm{min}$ ) and dynamic $(6.5 \mathrm{~m} / \mathrm{s})$ results were compared. However, in 2D laminates, Jackson et al. [38] recorded only $5 \%$ reduction when certain layups were compared. It is worth noting that Jackson et al. used much higher performance prepregs in their study. In complete contrast to those findings, PD3 specimens show a $5 \%$ increase in SEA achieved by the transition. Even with the $4.6 \%$ coefficient of variation in results for PD3 specimens (Table 3), there is no significant SEA decreased caused by the transition. One possible explanation for this retention of SEA is that in layer-to-layer architectures, both quasi-static and dynamic failure modes under axial crush in PD3 specimens are fibre dominated. Carbon fibres, unlike the matrix, are strain rate insensitive resulting in a lesser variation than in $2 \mathrm{D}$ composites in which splaying is matrix dominated. 


\section{Conclusions}

The main aim of this paper was to investigate how small variations within layer-to-layer 3D weave architectures influence the energy absorption performance and mechanical properties of 3D woven layerto-layer carbon-epoxy composites. Energy absorption, compression and flexural properties were generally improved by $19 \%, 18 \%$ and $72 \%$ respectively as the pick density was increased from PD1(lowest pick density) to PD3 (highest pick density). Quasi-static SEA was highest in PD1 specimens with an average value of $104 \mathrm{~J} / \mathrm{g}$. This is the highest quasi-static reported in a 3D woven composite reported to date. The high SEA in PD1 specimens reflects how closely PD1 specimens mimic 2D laminate layups with a high percentage of axial reinforcements alongside secondary hoop (transverse) reinforcement. Dynamic SEA was largest in the PD3 specimens, with a value of 93J/g. Dynamic SEA improvements were the result of increased fibre dominated failure in PD1 and PD3 specimens rather than matrix dominated failure in PD2 specimens. Failure mechanisms in quasi-static tests transitioned from splaying to more progressive folding, whereas all dynamic specimens displayed splaying failure. High pick density layer-to-layer specimens can provide particularly good dynamic performance compared to 2D laminates and some other types of 3D weaves, which is a useful property in the realm of real-world applications. The general improvement in crush efficiency (especially in the dynamic case) and mechanical properties is due to a combination of few factors - increased compactness, less resin rich areas, increased resistance to folding, higher number of interlocking points and increased friction between fronds. The improvements in SEA and mechanical performance in specimens were achieved with a relatively small change in manufacturing parameters (decreasing haul-off speed) rather than the rethreading of the loom, reducing manufacturing time and cost.

\section{Acknowledgements}

This work was supported by EU Horizon 2020 Marie Skłodowska-Curie Actions Innovative Training Network- ICONIC [grant agreement number: 721256]. The authors acknowledge the support from The Engineering Research Centre (ECRE) of Ulster University and Axis Composites Ltd, especially Roy Brelsford, Dr Glenda Stewart, Simon Hodge and Graeme Craig. 


\section{References}

[1] Farley GL. Energy Absorption of Composite Materials. J Compos Mater 1983;17:267-79. doi:10.1177/002199838301700307.

[2] Feraboli P, Deleo F, Garattoni F. Efforts in the standardization of composite materials crashworthiness energy absorption. Proc 22nd ASC Tech Conf Seattle, WA Sept 2007:17-20.

[3] Esnaola A, Tena I, Aurrekoetxea J, Gallego I, Ulacia I. Effect of fibre volume fraction on energy absorption capabilities of E-glass/polyester automotive crash structures. Compos Part B Eng 2016;85:1-7. doi:10.1016/j.compositesb.2015.09.007.

[4] Palanivelu S, Paepegem W Van, Degrieck J, Vantomme J, Kakogiannis D, Ackeren J Van, et al. Crushing and energy absorption performance of different geometrical shapes of small-scale glass/polyester composite tubes under quasi-static loading conditions. Compos Struct 2011;93:992-1007. doi:doi.org/10.1016/j.compstruct.2010.06.021.

[5] Palanivelu S, Van Paepegem W, Degrieck J, Van Ackeren J, Kakogiannis D, Van Hemelrijck D, et al. Experimental study on the axial crushing behaviour of pultruded composite tubes. Polym Test 2010;29:224-34. doi:10.1016/j.polymertesting.2009.11.005.

[6] Palanivelu S, Paepegem W Van, Degrieck J, Vantomme J, Kakogiannis D, Ackeren J Van, et al. Comparison of the crushing performance of hollow and foam-filled small-scale composite tubes with different geometrical shapes for use in sacrificial cladding structures. Compos Part B Eng 2010;41:434-45. doi:10.1016/j.compositesb.2010.05.009.

[7] Ramakrishna S, Hamada H, Maekawa Z, Sato H. Energy Absorption Behavior of Carbon-FiberReinforced Thermoplastic Composite Tubes. J Thermoplast Compos Mater 1995;8:323-44. doi:10.1177/089270579500800307.

[8] Hull D. A unified approach to progressive crushing of fibre-reinforced composite tubes. Compos Sci Technol 1991;40:377-421. doi:10.1016/0266-3538(91)90031-J.

[9] Schmueser DW, Wickliffe LE. Impact Energy Absorption of Continuous Fiber Composite Tubes. J Eng Mater Technol 1987;109:72. doi:10.1115/1.3225937.

[10] Warrior NA, Turner TA, Robitaille F, Rudd CD. Effect of resin properties and processing parameters on crash energy absorbing composite structures made by RTM. Compos Part A Appl Sci Manuf 2003;34:543-50. doi:10.1016/S1359-835X(03)00057-5. 
[11] Wang L. Review of Textile Composite Materials on Automotive Industry n.d.

[12] Goering J, Bayraktar H. 3D Woven Composites for Energy Absorption Applications. SPE Automot., 2016, p. 1-18. doi:10.4271/2016-01-0530.

[13] Saleh MN, Soutis C. Recent advancements in mechanical characterisation of 3D woven composites. Mech Adv Mater Mod Process 2017;3:12. doi:10.1186/s40759-017-0027-z.

[14] Tarfaoui M, Nachtane M, El Moumen A. Energy dissipation of stitched and unstitched woven composite materials during dynamic compression test. Compos Part B Eng 2019;167:487-96. doi:10.1016/j.compositesb.2019.03.023.

[15] Gao X, Tao N, Yang X, Wang C, Xu F. Quasi-static three-point bending and fatigue behavior of 3D orthogonal woven composites. Compos Part B Eng 2019;159:173-83. doi:10.1016/j.compositesb.2018.09.077.

[16] Bayraktar H, Ehrlich D, Goering J, Mcclain M, Composites AE, Hampshire N, et al. 3D Woven Composites for Energy Absorbing. 20th Int. Conf. Compos. Mater., 2015, p. 19-24.

[17] Wu Z, Wang M, Ying Z, Cheng X, Hu X. Influence of fabric architecture on crushing behavior of semi-hexagonal composite structures under axial loading. J Ind Text 2019;49:162-80. doi:10.1177/1528083718775977.

[18] Neale G, Dahale M, Yoo S, Toso N, McGarrigle C, Kelly J, et al. Improved Energy Absorption in 3D Woven Composites by Weave Parameter Manipulation. Procedia CIRP 2019;85:284-9. doi:10.1016/j.procir.2019.09.017.

[19] Gerlach R, Siviour CR, Wiegand J, Petrinic N. In-plane and through-thickness properties, failure modes, damage and delamination in 3D woven carbon fibre composites subjected to impact loading. Compos Sci Technol 2012;72:397-411. doi:10.1016/j.compscitech.2011.11.032.

[20] Luan K, Gu B. Energy absorption of three-dimensional angle-interlock woven composite under ballistic penetration based on a multi-scale finite element model. Int J Damage Mech 2015;24:320. doi:10.1177/1056789514520800.

[21] Boussu F, Cristian I, Nauman S. General definition of 3D warp interlock fabric architecture. Compos Part B Eng 2015;81:171-88. doi:10.1016/j.compositesb.2015.07.013.

[22] Stig F, Hallström S. Influence of crimp on 3D-woven fibre reinforced composites. Compos Struct 2013;95:114-22. doi:10.1016/j.compstruct.2012.07.022. 
[23] Dai S, Cunningham PR, Marshall S, Silva C. Influence of fibre architecture on the tensile, compressive and flexural behaviour of 3D woven composites. Compos Part A Appl Sci Manuf 2015;69:195-207. doi:10.1016/j.compositesa.2014.11.012.

[24] Dahale M, Neale G, Lupicini R, Cascone L, McGarrigle C, Kelly J, et al. Effect of weave parameters on the mechanical properties of 3D woven glass composites. Compos Struct 2019;223:110947. doi:10.1016/j.compstruct.2019.110947.

[25] Shigang A, Daining F, Rujie H, Yongmao P. Effect of manufacturing defects on mechanical properties and failure features of 3D orthogonal woven $\mathrm{C} / \mathrm{C}$ composites. Compos Part B Eng 2015;71:113-21. doi:10.1016/j.compositesb.2014.11.003.

[26] Gurit. Prime ${ }^{\mathrm{TM}}$ 20Lv Data Sheet 2015:1-6.

[27] TorayCA. T700S Technical Data Sheet 2005:2. doi:CFA-005.

[28] Dahale M, Neale G, Lupicini R, Cascone L, McGarrigle C, Kelly J, et al. Effect of weave parameters on the mechanical properties of 3D woven glass composites. Compos Struct 2019;223:110947. doi:10.1016/j.compstruct.2019.110947.

[29] Kohlgrueber D, Kamoulakos A. Validation of Numerical Simulation of Composite Helicopter Subfloor Structures under Crash Loading. Am. Helicopter Soc. 54th Annu. Forum, Washington DC: 1998.

[30] Feraboli P. Development of a Corrugated Test Specimen for Composite Materials Energy Absorption. J Compos Mater 2008;42:229-56. doi:10.1177/0021998307086202.

[31] Malcom AJ, Aronson MT, Wadley HNG. Three-dimensionally woven glass fiber composite struts: Characterization and mechanical response in tension and compression. J Compos Mater 2016;50:25-43. doi:10.1177/0021998315569751.

[32] Quinn JP, Mcllhagger AT, Mcllhagger R. Examination of the failure of 3D woven composites. Compos Part A Appl Sci Manuf 2008;39:273-83. doi:10.1016/j.compositesa.2007.10.012.

[33] Neale G. Effective Triggering of Omega-Shaped 3D Woven Composite Components for Progressive Crush Initiation. Sir Bernard Crossl. Symp. 2018, Dublin: 2018, p. 3.

[34] Carruthers JJ, Kettle AP, Robinson AM. Energy Absorption Capability and Crashworthiness of Composite Material Structures: A Review. Appl Mech Rev 1998;51:635. doi:10.1115/1.3100758. 
[35] Garattoni F. Crashworthiness and composite materials : development of an experimental test method for the energy absorption determination and. University of Bologna, 2011. doi:10.6092/unibo/amsdottorato/3287.

[36] ASTM INTERNATIONAL. D695: Compressive Properties of Rigid Plastics 12015. doi:10.1520/D0695-15.2.

[37] ASTM International. D7264/D7264M-15: Standard Test Method for Flexural Properties of Polymer Matrix Composite Materials 2015;i:1-11. doi:10.1520/D7264.

[38] Jackson A, Dutton S, Gunnion AJ, Kelly D. Investigation into laminate design of open carbonfibre/epoxy sections by quasi-static and dynamic crushing. Compos Struct 2011;93:2646-54. doi:10.1016/j.compstruct.2011.04.032.

[39] Priem C, Othman R, Rozycki P, Guillon D. Experimental investigation of the crash energy absorption of 2.5D-braided thermoplastic composite tubes. Compos Struct 2014;116:814-26. doi:10.1016/j.compstruct.2014.05.037.

[40] Hamada H, Ramakrishna S. Effect of Fiber Material on the Energy Absorption Behavior of Thermoplastic Composite Tubes. J Thermoplast Compos Mater 1996;9:259-79. doi:10.1177/089270579600900304.

[41] Boria S. Thin-walled truncated conical structures under axial collapse. Dyn. Response Fail. Compos. Mater. Struct., Elsevier; 2017, p. 335-63. doi:10.1016/B978-0-08-100887-4.00011-1.

[42] Mamalis AG, Manolakos DE, Demosthenous GA, Ioannidis MB. The static and dynamic axial crumbling of thin-walled fibreglass composite square tubes. Compos Part B Eng 1997;28:439-51. doi:10.1016/S1359-8368(96)00066-2.

[43] David M, Johnson AF, Voggenreiter H. Analysis of Crushing Response of Composite Crashworthy Structures. Appl Compos Mater 2013;20:773-87. doi:10.1007/s10443-012-9301-8.

[44] Liu Q, Ou Z, Mo Z, Li Q, Qu D. Experimental investigation into dynamic axial impact responses of double hat shaped CFRP tubes. Compos Part B Eng 2015;79:494-504. doi:10.1016/j.compositesb.2015.05.016. 
8. Figures
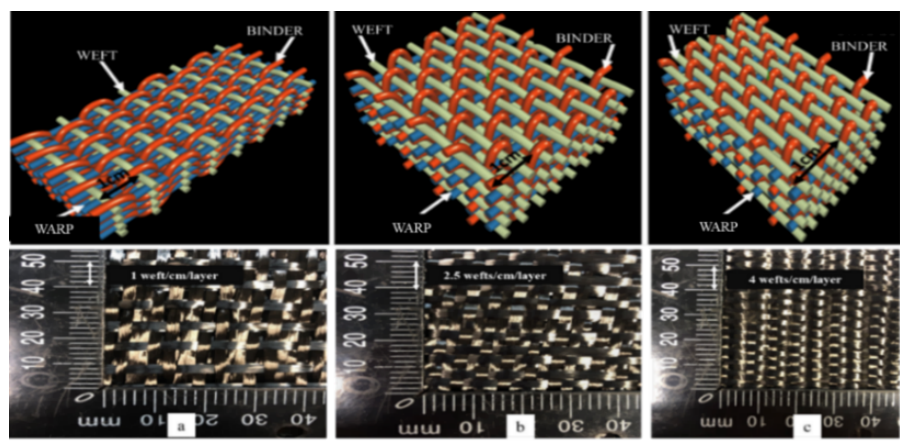

Figure 1: Diagrams of fabric architecture and 3D woven preform with (a) 4 picks $/ \mathrm{cm}$, (b) 10 picks $/ \mathrm{cm}$ and

(c) $16 \mathrm{picks} / \mathrm{cm}$.
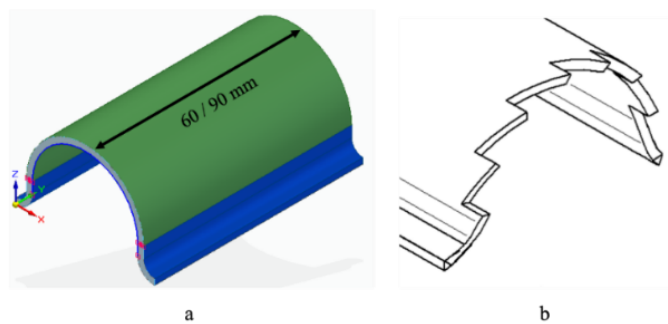

Figure 2: Diagram of (a) omega-shaped crush coupon geometry and (b) saw-tooth trigger.

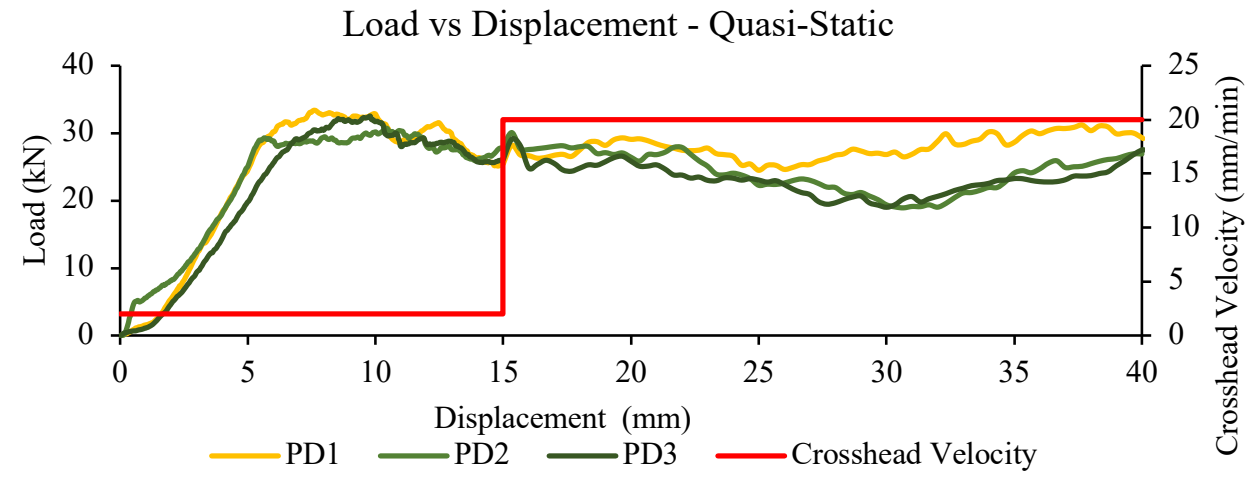

Figure 3: Typical load versus displacement curves comparing specimens crushed quasi-statically.

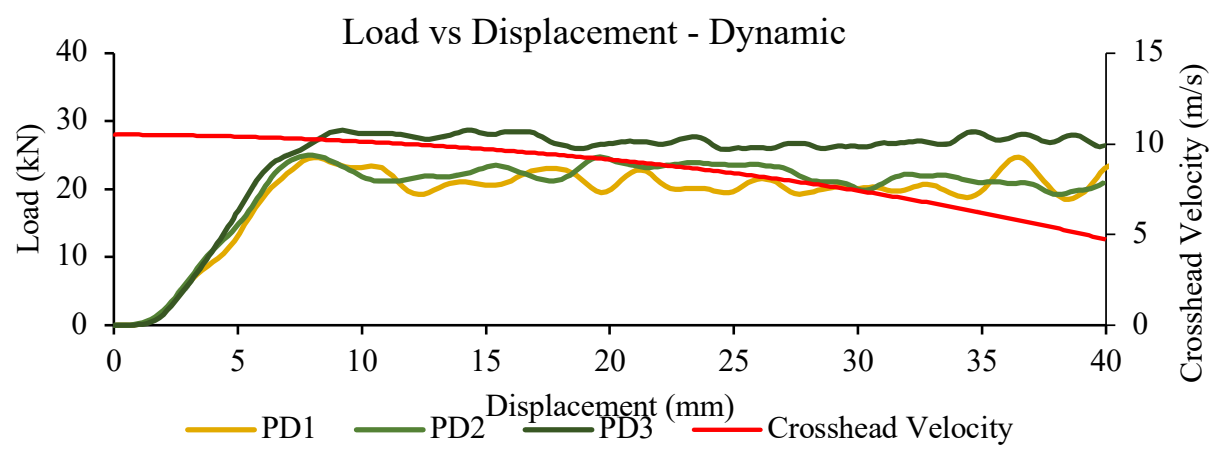


Figure 4: Typical load versus displacement curves comparing specimens crushed dynamically.

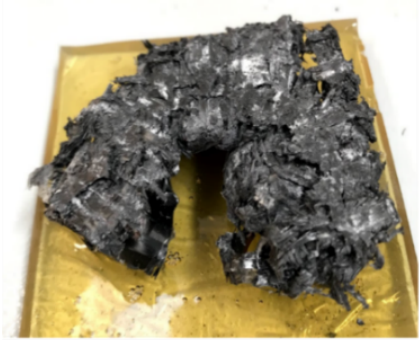

a

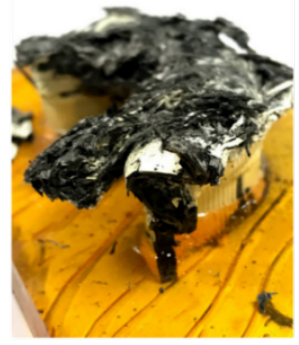

b

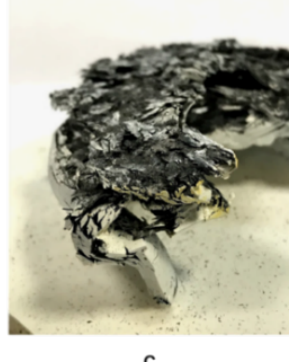

Figure 5: Final crush geometry images showing (a) splaying in PD1 (b) splaying and folding in PD2 and (c) folding in PD3specimens.

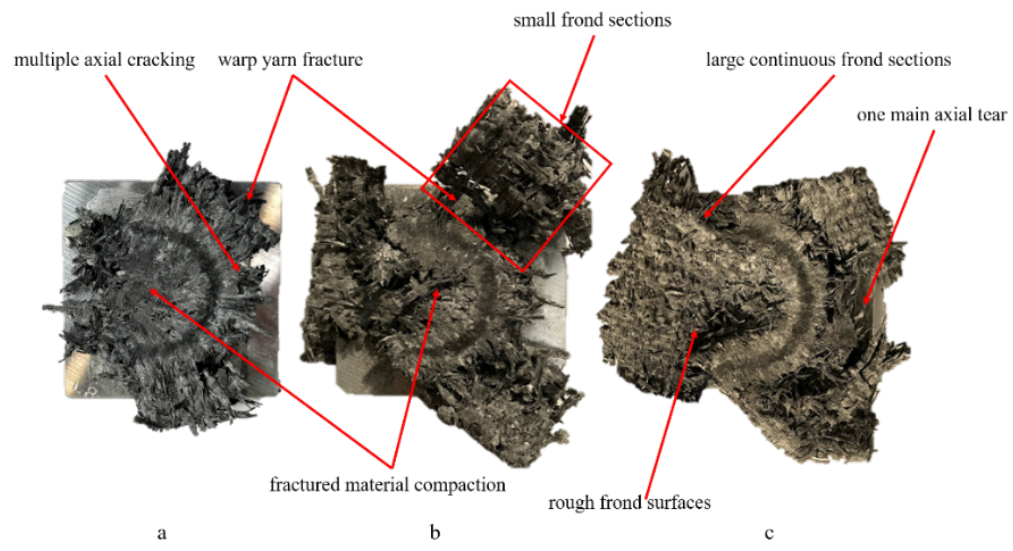

Figure 6: Final crush geometry images showing splaying in (a) PD1 (b) PD2 and (c) PD3 specimens in the dynamic regime.

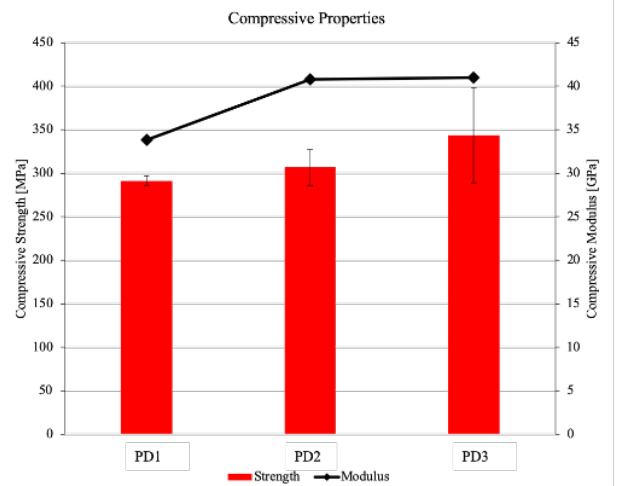

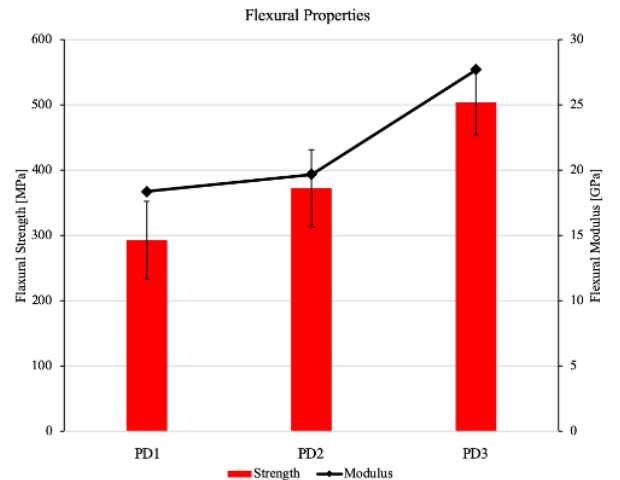

Figure 7 Compression and Flexure properties of PD1, PD2 and PD3 specimens. 


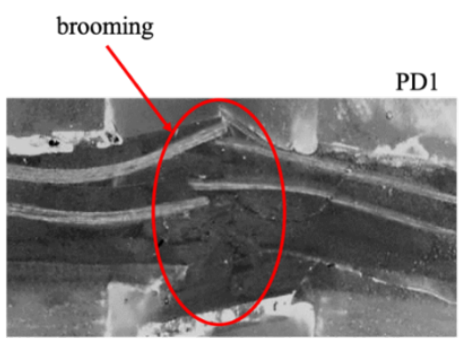

a

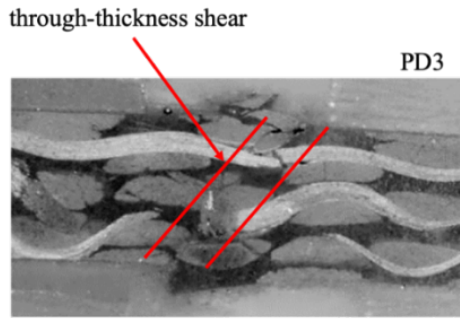

b

Figure 8: Micrographs showing warp direction compressive failure in (a) PD1 and (b) PD3 specimens.
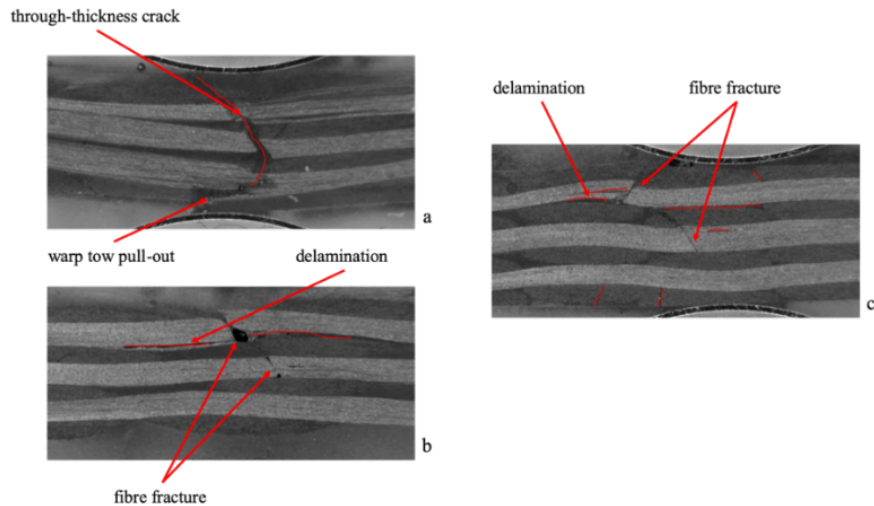

Figure 9: Micrographs showing warp direction flexural failure in (a) PD1, (b) PD2 and (c) PD3 specimens.

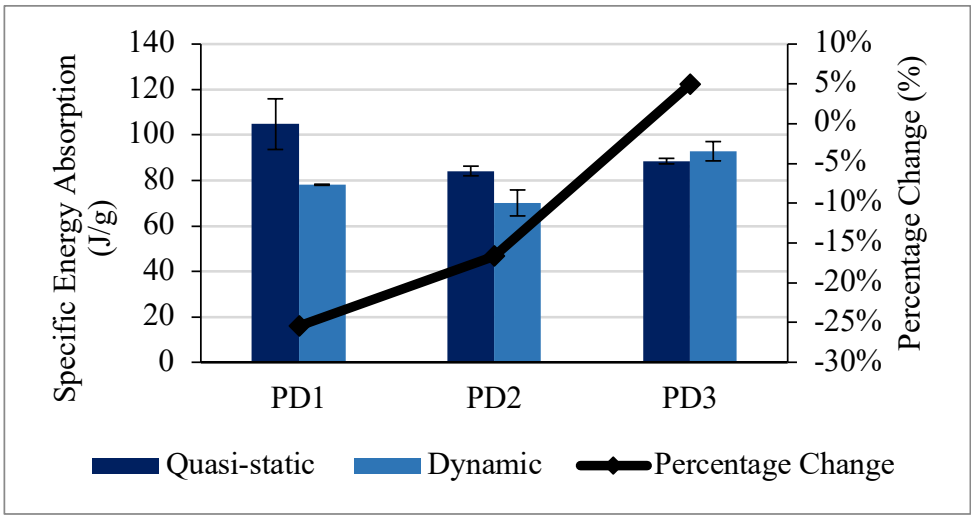

Figure 10: Comparison of average SEA values for specimens of varying pick density.

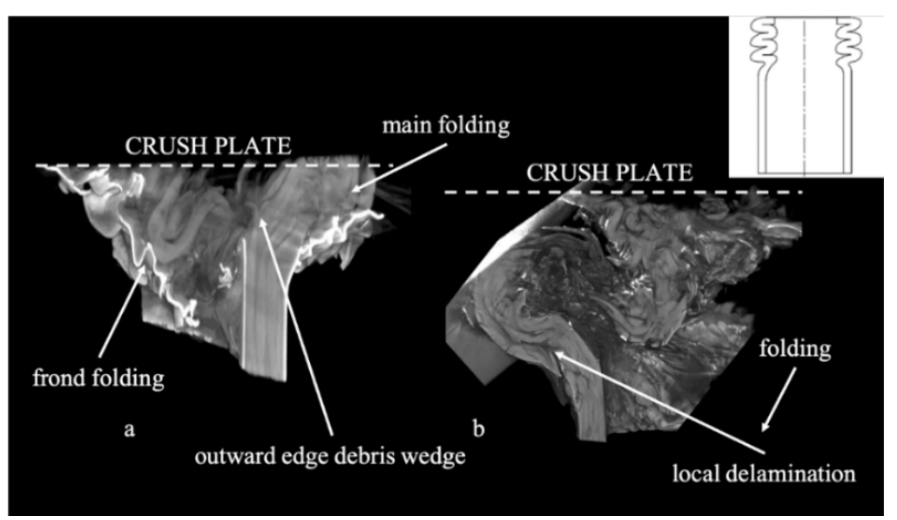


Figure 11: Micro-CT images of the crush zone in (a) PD1 and (b) PD2 specimens

9. Tables

Table 1: Table showing the variation in preform parameters between specimens

\begin{tabular}{|c|c|c|c|c|c|c|c|c|}
\hline \multirow{2}{*}{ Specimens } & \multirow{2}{*}{ Wefts/cm } & \multirow{2}{*}{ Warps $/ \mathbf{c m}$} & \multirow{2}{*}{$\begin{array}{l}\text { Areal } \\
\text { Density } \\
\left(\mathrm{kg} / \mathrm{m}^{2}\right)\end{array}$} & \multicolumn{3}{|c|}{ Yarn content $(\%)$} & \multicolumn{2}{|c|}{ \%Tow Crimp } \\
\hline & & & & Warp & Weft & Binder & Warp & Weft \\
\hline PD1 & 4 & 12 & 1.26 & 37.5 & 25 & 37.5 & 5.5 & 1.8 \\
\hline PD2 & 10 & 12 & 1.45 & 27.2 & 45.5 & 27.2 & 3.7 & 1.4 \\
\hline PD3 & 16 & 12 & 2.23 & 21.4 & 57.2 & 21.4 & 2.8 & 1.3 \\
\hline
\end{tabular}

Table 2: Crush specimen characteristics.

\begin{tabular}{lllll}
\hline Specimen Type & Mass Per Unit $\mathbf{m m}(\mathbf{g} / \mathbf{m m})$ & $\begin{array}{l}\text { Volume } \\
\text { Fraction } \\
\text { [warp/weft } \\
\text { ] } \mathbf{( \% )}\end{array}$ & $\begin{array}{l}\text { Average } \\
\text { Thicknes } \\
\mathbf{s}(\mathbf{m m})\end{array}$ & Number of Specimens \\
\hline PD1 & 0.266 & $44 / 32$ & 2.5 & 3 quasi-static, 3 dynamic \\
\hline PD2 & 0.298 & $44 / 40$ & 2.9 & 3 quasi-static, 3 dynamic \\
\hline PD3 & 0.290 & $44 / 53$ & 2.9 & 3 quasi-static, 3 dynamic \\
\hline
\end{tabular}

Table 3: Crush test results for quasi-static and dynamic specimens.

\begin{tabular}{|c|c|c|c|c|c|c|c|c|}
\hline \multirow[b]{2}{*}{$\begin{array}{l}\text { Specime } \\
\text { n Type }\end{array}$} & \multicolumn{2}{|c|}{$F_{\max }(k N)$} & \multicolumn{2}{|c|}{$F_{\text {avg }}(k N)$} & \multicolumn{2}{|c|}{ SEA (J/g) } & \multicolumn{2}{|c|}{ CFE (\%) } \\
\hline & $\begin{array}{l}\text { Ave } \\
\text { rage }\end{array}$ & $\begin{array}{l}\text { Coeff. of } \\
\text { Variation } \\
{[\%]}\end{array}$ & $\begin{array}{l}\text { Ave } \\
\text { rage }\end{array}$ & $\begin{array}{l}\text { Coeff. of } \\
\text { Variation } \\
{[\%]}\end{array}$ & $\begin{array}{l}\text { Ave } \\
\text { rage }\end{array}$ & $\begin{array}{l}\text { Coeff. of } \\
\text { Variation } \\
{[\%]}\end{array}$ & $\begin{array}{l}\text { Ave } \\
\text { rage }\end{array}$ & $\begin{array}{l}\text { Coeff. of } \\
\text { Variation } \\
{[\%]}\end{array}$ \\
\hline PD1 & 32.6 & 1.6 & 30.5 & 3.6 & $\begin{array}{l}104 . \\
8\end{array}$ & 10.6 & 93.4 & 3.6 \\
\hline PD2 & 28.8 & 6.9 & 27.6 & 0.9 & 84.2 & 2.5 & 96.4 & 6.3 \\
\hline PD3 & 33.3 & 3.3 & 27.5 & 4.3 & 88.5 & 1.4 & 82.5 & 2.2 \\
\hline $\begin{array}{l}\text { PD1- } \\
\text { DYN }\end{array}$ & 24.8 & 2.6 & 20.5 & 1.3 & 78.1 & 0.3 & 84.1 & 0.6 \\
\hline $\begin{array}{l}\text { PD2- } \\
\text { DYN }\end{array}$ & 23.9 & 3.9 & 20.5 & 5.2 & 70.1 & 8.1 & 85.9 & 1.4 \\
\hline $\begin{array}{l}\text { PD3- } \\
\text { DYN }\end{array}$ & 28.6 & 0.0 & 26.6 & 1.9 & 92.9 & 4.6 & 93.0 & 1.9 \\
\hline
\end{tabular}

